\title{
G protein-Coupled Receptor Distribution Impacts the Effectiveness of Signal Transmission
}

\author{
Ming-Yi Zhou' ${ }^{1}$, Ya-Yu Hu${ }^{1}$, Huai-Hu Chuang*
}

Institute of Molecular Biology, Academia Sinica, Taipei Taiwan 11529

*To whom correspondence should be addressed: Huai-hu Chuang, Institute of

Molecular Biology, Academia Sinica, Taipei, Taiwan 11529;

huaihu@gate.sinica.edu.tw; Tel. 886-2-2789-9984

${ }^{1}$ These two authors contribute equally.

\begin{abstract}
Numbers of activated receptor dictate efficacy of neurotransmitter stimulation. Many PLC coupled receptors activated by ligands elicit canonical downstream Gq/11 pathway to induce endogenous $\mathrm{Ca}^{2+}$ gated chloride channels. The coupling from receptors to effectors was analyzed in Xenopus oocytes expressing genetically modified angiotensin receptor type 1 receptor (AT1R). The latency between ATII binding and $\mathrm{Ca}^{2+}$-induced $\mathrm{Cl}^{-}$current surge was inversely correlated. AT1R activation triggered a chain of chemical reactions, of which the products were playing messengers for subsequent events. Messenger accumulation must rate-limit the agonism. For accurate quantification the speed of ATII triggered the $i \mathrm{Cl}^{-}$. The T-form AT1R-IRK1 fusion exhibits faster induction compared to the M-form. The latency of the recorded none vanished $i \mathrm{Cl}^{-}$, marking the lowest genuine calcium activation, took place at earlier time point by the timer time. The evoked $i \mathrm{Cl}^{-}$however reached similar maximal amplitudes. This kinetic effect raises the possibility to use temporal coding to complement amplitude coding (analogous to FM versus AM radio transmission) for receptor-agonist pairs.
\end{abstract}

Keywords: G protein-coupled receptor (GPCR), inwardly-rectifying potassium channel 1 (IRK1), angiotensin II type 1 receptor (AT1R), angiotensin II (ATII), twoelectrode voltage clamp (TEVC), calcium-activated chloride channel (CaCC), 


\section{Introduction}

There are several families of transmembrane proteins encoded by almost a thousand genes that are critical for normal physiology, with $G$ protein-coupled receptors (GPCRs) being the largest and most ubiquitous [1]. The highly specific ligand-GPCR interaction prompts an efficient cellular response, which is vital for the health of cells and organisms. GPCRs share seven conserved membrane-spanning alpha-helical transmembrane domains that are activated by ligand binding in the extracellular space [2, 3]. Through conformational changes, ligand-bound GPCRs activate heterotrimeric G-proteins, which execute the downstream signaling pathways through recruitment and activation of cellular enzymes [4].

Up to $40 \%$ of drugs target GPCRs [5]. Despite considerable progress in using GPCRs as drug targets, our understanding of how these drugs act on GPCRs remains incomplete. GPCRs can be activated by different ligands to transduce similar signaling pathways. Previous studies employing various techniques including fluorescence microscopy, crystallography or theoretical modeling have revealed aspects of GPCR signaling transduction at the molecular level [6-11]. However, since the receptortransducer complex is highly dynamic and can adopt many conformational transitions, it is virtually impossible to use crystallographic techniques alone to capture all conformational states of either bound or unbound GPCRs. Moreover, the resolution of conventional methods is insufficiently sensitive to quantify small changes in receptor number. Time-resolved measurements are essential to characterize the order of events leading to formation of GPCR-transducer complexes, especially when paired with complementary functional studies.

Angiotensin II type 1 receptor (AT1R) belongs to a subtype of GPCRs [12, 13] and plays an critical role in modulating hypertension [14]. AT1R has been identified in a wide variety of tissues including the kidney, liver, adrenal gland, cardiovascular system, and brain [15-17]. Upon binding to angiotensin II (ATII), AT1R is stabilized in its active conformation and stimulates heterotrimeric $G$ proteins. $G$ proteins dissociate into alpha (Gq/11 family) and beta/gamma subunits. AT1R interacts primarily with $\mathrm{Gq} / 11$ proteins in many ATII target cells [18, 19]. Gq/11 subunits act as signal transducers to activate phospholipase C (PLC), leading to hydrolysis of phosphatidylinositol 4,5-bisphosphate ( $\left.\mathrm{PIP}_{2}\right)$ and formation of diacylglycerol (DAG) 
and inositol trisphosphate $\left(\mathrm{IP}_{3}\right)$. DAG and IP3 stimulate the endoplasmic reticulum (ER) to release intracellular $\mathrm{Ca}^{2+}[20-25]$.

In the brain, many hormones and neurotransmitters activate cellular signal transduction pathways via G-protein coupled receptors [26, 27]. Ga proteins are speedily activated upon the formation of ternary complexes from direct interaction of receptors with their cognate ligands. Among a collection of PLC-coupled GPCR pathways, despite all signaling through the canonical Gaq and downstream effectors thereof, each receptor still elicits events of a distinct spatiotemporal profile. To elucidate the basis on which such versatility arises, we performed single cell analysis to monitor GPCR activation in real time.

Receptor-effector coupling is an under-studied step in signal transmission. The analytical process is inherently complex given that relevant factors determining the outputs in either upstream or downstream end are usually multifactorial so that the outputs have a wide dynamic range [28-32]. Such data scattering obscures the underlying mapping from inputs to outputs. To address the basis of coupling efficiency, the derived quantity from both ends of the equation must be accurately measured; analysis of coupling also demands a range of inputs evenly distributed in the spatial as well as time domain in the broadest technique-possible range, especially for deriving the threshold of signal induction at which the receptor number would expectedly be so low as to hamper its precise measurement. Therefore, we use sensitive and precise electrophysiological methods to uncover the usually accompanied low-level expression.

Xenopus oocytes are a widely used model for studying heterologous expressed receptors, transport proteins, and ion channels. To answer the coupling mechanism by which GPCRs transduce downstream signaling, the high level of endogenous $\mathrm{Ca}^{2+}$ activated $\mathrm{Cl}$ channels (CaCCs) could be measured as a reporter. CaCCs are activated by elevated intracellular $\mathrm{Ca}^{2+}$ concentrations regardless the $\mathrm{Ca}^{2+}$ source. When the $\mathrm{Ca}^{2+}$ concentration reaches a sufficiently high threshold, the chloride channel opens to allow significant $\mathrm{Cl}^{-}$efflux. Thus, GPCRs induce signaling events to convey a rapid sub-plasma membranous $\mathrm{Ca}^{2+}$ concentration rise, which could be detected precisely by the conducted $\mathrm{Cl}^{-}$current through $\mathrm{CaCC}$.

We considered that the numbers of AT1R receptor dedicate the rate of the ATIIinduced chloride currents responses; more AT1R receptor numbers would have a faster response rate. In this study, we selected inwardly rectifying $\mathrm{K}^{+}$channel (IRK1), an ion 
channel insensitive to most known cytosolic messengers and cellular modulators [3336], to construct a receptor-channel fusion. We found that this method can accurately calculate AT1R receptor numbers by measuring potassium flux through recombinant receptors expressed in Xenopus laevis oocytes. With agonists bound to the AT1R receptors, the resulting activated $\mathrm{G}$ proteins induced downstream pathways by elevating intracellular $\mathrm{Ca}^{2+}$ concentrations to induce $\mathrm{Cl}^{-}$flux, allowing us to investigate the relationship between receptor numbers and the rate of chloride current production. 


\section{Results}

\section{Expression of M-form and T-form of AT1R-IRK1 fusions in Xenopus oocytes}

We developed a technique to indirectly infer the number of G-protein receptors expressed by detecting channel currents, and to quantify the efficiency of the receptors. By generating fusions of receptors and channels together, the ion channel activity could serve as the readout for receptor activation. We have designed the pGEMHE vector with elements that enable efficient protein expression in the Xenopus oocytes (Figure 1A). A fused sequence with the AT1R gene linked to an inwardly rectifying potassium channel $\mathrm{K}_{\mathrm{ir}} 2.1$ (IRK1) gene, which was engineered into the pGEMHE to generate AT1R-IRK1 fusion proteins (Figure 1B). We constructed two types of fusion proteins, M-form and T-form of AT1R-IRK1. The M-form fusion protein includes an AT1R fused with an IRK1 subunit, whereas the T-form fusion protein has an AT1R linked to a tetrameric tandem string of IRK1 subunits. Since four IRK1 subunits form a functional tetrameric $\mathrm{K}$ channel [41], the M-form of AT1R-IRK1 represents a functional IRK1 channel linked four AT1R receptors and the T-form of AT1R-IRK1 represents a functional IRK1 channel linked an AT1R receptor.

\section{Functional IRK1 in M-form and T-form of AT1R-IRK1}

We utilized the two-electrode voltage-clamp technique to record potassium currents by Ramp program (Figure 2A). To confirm that the function of IRK1 channels is not be altered, we examined the IRK1 currents in oocytes expressing M-form or T-form of AT1R-IRK1 with the voltages from -120 to $+80 \mathrm{mV}$ in $600 \mathrm{~ms}$. We showed that the AT1R-IRK1 fusion proteins expressed heterologously in Xenopus oocytes with biophysical hallmarks of IRK1, including high $\mathrm{K}^{+}$selectivity and strong rectification. The current-voltage (IV) curves of the M-form and the T-form AT1R-IRK1 showed no difference to IRK1 alone (Figure 2B). These results indicate that IRK1 is functional when fused to the AT1R, and the recorded $\mathrm{K}^{+}$currents might be suitable for measuring the numbers of AT1R.

While Xenopus oocytes are an outstanding heterologous expression system for investigating ion channel activity, the oocytes express an amazing variety of endogenous potassium ion channels that can interfere with electrophysiological measurements. Therefore, we recorded the endogenous potassium current in uninjected oocytes. In the $\mathrm{K}^{+}$-free, $96 \mathrm{mM} \mathrm{NaCl}$ perfusion solution, the basal current was nearly 0 
nA (Figure 2C). In the $96 \mathrm{mM} \mathrm{K}^{+}$solution, the oocyte endogenous potassium currents were around 50 to $60 \mathrm{nA}$ in the voltage range of $-94 \mathrm{mV}$ to $-114 \mathrm{mV}$. These recorded potassium currents in uninjected oocytes were used as basal control. Then we examined the IRK1 currents in oocytes injected with RNA of M-form or T-form AT1R-IRK1. Both basal currents recorded from $\mathrm{M}$-form and T-form in the $96 \mathrm{mM} \mathrm{NaCl}$ solution showed no difference to the basal current recorded from the uninjected oocytes (Figures 2D and 2E, left panels). After perfusing with $96 \mathrm{mM} \mathrm{K}^{+}$solution, the injected M-form RNA or T-form RNA showed a significant IRK1 current, respectively (Figures 2D and 2E, right panels). These results indicate that the IRK1 channels in M-form and T-form AT1R-IRK1s are functional.

\section{Quantifying AT1R numbers from recorded potassium currents}

Next, we tried to use the IRK1 currents to measure numbers of AT1R. Previous study showed that IRK1 single channel conductance is around 21pS (Aleksandrov A., et al. 1996) at $150 \mathrm{mM} \mathrm{K}^{+}$solution, which was employed as IRK1 single conductance in the calculation. We measured the conductance stable change (slop) region of recorded current trace (at -114 -94 mV, purple boxes in Figures 2C-E). The average conductance change from ten repeated recordings was further divided by the value of IRK1 single-channel conductance. The values of calculation showed the numbers of IRK1 expressed at the oocyte surface, which means numbers of AT1R as well. Both M-form and T-form of AT1Rs were obtained in increasing amounts of AT1R-IRK1 fusion RNAs injected into oocytes, thereby allowing us to establish how differential expression of fusion proteins drove the observed phenotypes.

Next, we examined the relationship between the concentration of injected RNA and numbers of AT1R-IRK1 fusions. With increasing RNA concentrations, both receptor numbers of M-form and T-form AT1R-IRK1 increased accordingly. In Mform, the amounts of RNA ranging from 5 to $4,000 \mathrm{pg}$ were injected. We found that in some cases the maximum receptor number could reach as many as 60 millions. The average maximum receptor number is at about 30 millions with injection of 2,000 pg of RNA, which could not be further boosted by increasing the amount of injected RNA to $4,000 \mathrm{pg}$. Also, the minimal RNA required to elicit significant response is $50 \mathrm{pg}$ (Figure 3A). In T-form, the RNA amounts ranging from $0.5 \mathrm{pg}$ to $4,000 \mathrm{pg}$ were injected. Interestingly, $1 \mathrm{pg}$ of RNA was sufficient to elicit $\mathrm{K}^{+}$current for measurement, 
and the average maximum receptor number is at 10 millions with injection of 2,000 pg RNA. Independent maximum receptor numbers could reach as high as 20 millions (Figure 3B). These data showed that the minimal and maximal receptor numbers expressed in oocytes between $\mathrm{M}$-form and T-form are different. The difference in the $\mathrm{M}$-form and T-form in converting injected RNA into the oocytes to the measured active receptor numbers on the surface could be several folds (see Discussion). We believe that the measured $\mathrm{K}^{+}$current better reflects the number of active receptors on the surface than the amount of injected RNA, which are used for further study.

\section{ATII induced calcium-activated chloride currents in AT1R-IRK1 receptors}

To understand the efficiency of response rate, we measured the activity of AT1R receptor in the presence of the agonist angiotensin II (ATII). When ATII binds to AT1R receptor, active G-protein generates a cascade of downstream signaling transduction, inducing $(\mathrm{CaCC})$ open and $\mathrm{Cl}^{-}$efflux. To calculate the correlation between the number of AT1R and the maximum $\mathrm{Cl}^{-}$current of $\mathrm{CaCC}$, we established a continue Ramp with totally 610 repeats. Both $\mathrm{M}$-form and T-form were tested (Figure 3A). Because the rate of signal transduction downstream in the whole cell is constant, the time from the activation of AT1R to the peak chloride current (latency, Figure 3B) should be proportional to the amount of total activated AT1R on the cell surface. With the addition of agonist ATII, the first peak of the chloride current was recorded within 640 $\mathrm{ms}$ (ramps) from $+59 \mathrm{mV}$ to $+79 \mathrm{mV}$ of Ramp (Figure 3C). The basal current obtained from ten consecutive points prior to the application of ATII was subtracted from the measured chloride current to establish the activated chloride current.

Next, we examined whether the function of AT1R functions would be altered. While the $\mathrm{K}^{+}$current was recorded, the $\mathrm{Cl}^{-}$current was also measured in both M-form and T-form upon the ATII application. The detection of $\mathrm{Cl}^{-}$currents in both AT1RIRK1 fusions suggests that function of AT1R normally in both M-form and T-form fusions (Figure 3D).

\section{T-form of AT1R-IRK1 exhibits higher chloride current induction efficiency than M-form of AT1R-IRK1}

The receptors of the cells appear randomly and uniformly, and the individual responses to stimuli should be consistent. We investigate whether receptor distribution 
affects the efficiency of whole cells response. We plotted the response rate of ATIIinduced $\mathrm{Cl}^{-}$current against the number of AT1R-IRK1 fusions. With low number of Mform receptors ( $\sim$ a few millions), the response rate was very low. With increasing receptors, the response rate increased linearly and reached plateau when the receptor number reaching over 40 millions (Figure 4A). This result indicated that the response rate of $\mathrm{M}$-form fusion has the maximum close to the $0.2 \mathrm{~s}^{-1}$. Interestingly, the T-form fusion response rate also increased quickly and semi-linearly even in the range of a few millions receptor, reaching $0.2 \mathrm{~s}^{-1}$ with fewer than 20 millions (Figure 4B). Therefore, the response rate on the number of receptors for binding to the agonist ATII indicates that T-form AT1R-IRK1 has a higher signal transmission rate than that of M-form AT1R-IRK1.

We assessed the minimum number of receptors required to transduce extracellular signals into oocyte responses. Our use of $\mathrm{Ca}^{2+}$-activated $\mathrm{Cl}^{-}$current as a powerful reporter considerably enhanced the sensitivity of our assay. We plotted a cumulative probability distribution curve against the number of receptors within 1 million (Figure 4C, 4D). The M-form fusion showed that there was no detectable $\mathrm{Cl}^{-}$current production below $2 \times 10^{5}$ receptors. Even administrating the higher concentration of ATII, undetectable $\mathrm{Cl}^{-}$current response was produced (data not show). Between 2-7 x 105 receptors, stochastic responses were still detected. With more than $7 \times 10^{5}$ receptors, consistent responses were ensured in each RNA injection. The T-form fusion showed that detectable $\mathrm{Cl}^{-}$current was produced even at $1 \times 10^{5}$ receptors, and consistent responses were detected with more than $6 \times 10^{5}$ receptors. For T-form fusion proteins, $50 \%$ successful ATII-induced stimulation occurs when fewer than $3 \times 10^{5}$ receptors were present or, to be more accurately, agonist-bound receptors are present on an oocyte, whereas for M-form receptors, that number is $5 \times 10^{5}$ receptors (Figure 4D). The results show that M-form and T-form fusion receptors show different response probability and cell sensitivity.

Thus, physiologically, ATII must act on a sufficient number of receptors on a cell membrane to trigger downstream cell responses. Thus, when an oocyte has up to $\sim 7 \mathrm{x}$ $10^{5}$ agonist-bound receptors on an oocyte, the T-form has a higher probability of inducing $\mathrm{Cl}^{-}$current responses than the $\mathrm{M}$-form, a surprisingly novel result. 


\section{Discussion}

In this study, the AT1R was made into a channel fusion to facilitate synchronous receptor counting and concurrent monitoring of ligand-induced response. We could quantitatively the response for AT1R according to the receptor numbers of each. Thanks to the selectivity of potassium channels, we could separate the K-currents from a mixture of currents by simple ion replacement. We deduced the receptor number by measuring the whole cell current in $\mathrm{K}^{+}$containing solutions, subtracting the background non-K current in the $\mathrm{K}^{+}$free condition. The net $\mathrm{K}$ currents were converted into the number of receptors by dividing to the single channel conductance. This measurement is simple, direct, and stoichiometrically proportional. We set up a wide dynamic range of receptor expression, granting the subsequent quantitative analysis for coupling. The question we asked first was how many receptors would a cell need in order to initiate a whole-cell agonist response, i.e., the neurotransmitter induced calcium-activated chloride current?

Multiple studies have demonstrated that many GPCRs exist as dimers or high oligomers $[42,43]$. Some of these studies have also shown that GPCR dimerization or oligomerization is important for receptor function, including in relation to agonist affinity, potency, and efficacy, as well as G protein specificity [44-48]. Moreover, upon ligands binding to receptors, activated $\mathrm{G}$ proteins induce conformational changes of the receptors that may influence the function of other proximal receptors. Thus, the distance between receptors may alter their functions [49-51] .

We created the one-to-one receptor-channel fusion. The receptor portion of the fusion was directly ligated to a tandem tetrameric IRK1, T-form of AT1R-IRK1. By this design, no local high receptor density would be possible. If expressed at low enough level, one would not anticipate the receptors formed on the cell surface capable of assembling into local complexes. With the limitation of receptor numbers in oocytes membrane, the fusion of an IRK1 subunit by design must use their hydrophobic surface to assemble into tetrameric channels (a 4-receptor-to-1 receptor-channel design), Mform of AT1R-IRK1, which should bring the ligand binding sites physically closer than the 1-to-1 isomers in limitation of spatial distribution in oocytes membrane. However, someone might suspect that the creation of linked tandem receptor had created the higher-order receptor tetramers. With four AT1Rs fused to an IRK1 channel possibly caused unintentional and unnatural alteration of the receptor activity. Surprisingly, 
these two different designs did not display any measurable functional differences in receptor-effector coupling.

However, cell membrane package of M-form and T-form receptors could be very different. Our examination of chloride current response latencies reveals that, to exert the same oocyte activation rate, fewer T-form agonist-bound receptors are required than M-form receptors. Reduced the latency does not necessarily mean a stronger chloride current response. There are some exceptions that short latency was accompanied with smaller $\mathrm{Cl}^{-}$current response. But by and large, short latency was associated with a larger $\mathrm{Cl}^{-}$current which fired more readily. It is possible that quarternary structures of the $\mathrm{M}$ form are more constrained than for the T-form. The physical distances between agonist (ATII) binding sites in oocytes harboring M-form receptors may be closer than for those hosting the T-form because formation of a channel pore in the former necessitates proximity of four IRK1 subunits whereas, in the latter, each agonist binding site is independent.

The spatial distribution of AT1R receptor raises the possibility of using temporal coding to complement amplitude coding for receptor-agonist pairs. This situation is likely to FM versus AM radio transmission. Adequate receptor numbers located at the appropriate sites can produce responses, while insufficient or superabundant receptor numbers, or their locations too crowded or too loose may not able to induce the responses. In our study indicated that at the same receptor numbers, T-form of AT1RIRK1 have rapid $\mathrm{Cl}^{-}$current response rate than $\mathrm{M}$-form of AT1R-IRK1. This phenomenon suggested that AT1R receptor sites of M-form are so crowded that each receptor coupled $\mathrm{G}$ protein influences each other to their downstream signaling pathway.

The receptor-channel fusion had been a convenient and effective intermediate tool for counting the number of the receptors. The inherent risk of building a complex not already existing in nature is failure to form the intended structure because of folding problems ending in low yield, insolubility or accelerated degradation. We bypassed this stage and got the designated proteins made in the Xenopus oocytes. The engineered protein expressed sufficiently and folded properly and targeted to the expected destination. In the functional analysis, they behaved similar to their native counterparts.

Receptor-effector coupling depends upon every element involved in between [52]. To obtain a response, receptor number must reach a threshold to set off the 
cascade activation of $\mathrm{CaCC}$. The timing of the $\mathrm{CaCC}$ chloride current surge upon receptor activation, i.e. latency of the response, is a measurable indicator with which we can analyze the coupling efficiency between the upstream events and the effectors responses, ligand exposure on the surface and the calcium store release and any other responses following respectively. Typically, a period of membrane quiescence named latency was noted between exposure to soluble ligands from external leaflet and a rise of $\mathrm{Cl}$ current amplitude peaking shortly. Albeit the current amplitudes widely variable, latencies remain simple and robust for easy recording and subsequent detailed analysis.

When ATII binds to AT1R, not only may it activate Gq protein to induce the $\mathrm{IP}_{3}$ downstream pathway but it can activate another G protein, Gi, to induce the cAMPdependent pathway [53-55]. If $\mathrm{Gq}$ protein levels are too low to induce sufficient calcium release from the ER, CaCCs may not be activated, thereby preventing the generation of chloride current. Differential ligand binding affinities may also explain the variation in chloride current elicited by $\mathrm{T}$-form and $\mathrm{M}$-form receptors. Due to conformational changes in receptors upon ligand binding, $\mathrm{G}$ protein coupled efficiency may be potentially different for T-form or M-form receptors.

The acceleration of $\mathrm{CaCC}$ activation presents itself as a reduction of latency. Spatial expansion of the signal-transducer-acting domain should endow an increase of downstream response amplitudes or reduction of failure rates along coupling. We systematically varied the receptor numbers or altered the arrangement of relative spatial positions for agonist binding. This analysis is more sensitive and of higher precision than the direct measurement of delay, promising the potential of receptor activity for more incisive modeling. It opens the gate to revisit GPCR action wanting more general and useful parametric values in quantitative analyses, for instance, partial agonism or spared receptors.

In our study, we measured the time required between binding of angiotensin and the onset of chloride currents, latency. It is a reproducible receptor-ligand pair specific parameter. The application of ATII to a cell expressing ATIIR-fusion activated Gaq, hence the downstream chloride currents, which always display a waiting period with electrical quiescence. It reflected the delay to the time-dependently accumulate second messengers $\mathrm{Ca}^{2+}$. The latency was rate-limited by the production of GTP bound Gaq before the system reached the saturation expression of receptor. Expectedly, the latency 
was inversely correlated to the receptor expression level. It therefore indicated how effective the receptor activation was translated into an ionic response.

In sum, the AT1R-IRK1 fusion expressed as a full length polypeptide folded properly for both moieties; it gave rise to a strongly inwardly rectifying potassium channel with an unchanged single channel conductance; the receptor portion behaved like the parental GPCR with the identical ligand recognition; above all, activation by cognate agonists were of the same specificity and affinity. Application of neurotransmitters set off the coupling to the chloride channel $\mathrm{CaCC}$. The more the $\mathrm{K}$ currents were the speedier the onset of $\mathrm{CaCC}$, shown from the shortened latency. Reciprocals of latencies indicated how rapidly the effector response starts. Provided that receptor numbers were sufficiently low, the latency would be long enough to make confident measurements revealing the efficiency of receptor-effector coupling. We chose latency measure instead of other parameters particularly the size of $\mathrm{CaCC}$ to score post-receptor events to avoid over-amplification of downstream response thereby weakened quantitative causal relationship. The shortened latencies indicated an increase of speed of cytosolic calcium rise, a consequence of the $\mathrm{IP}_{3}$ surge. A larger post-receptor response arises from multiple steps of amplification. Although all three receptors we chose for latency analyses coupled to the same pathway, their coupling efficiencies differed. Importantly, the thresholds of upstream triggers depended on the intrinsic threshold for $\mathrm{Ca}$ activation of $\mathrm{CaCC}$. By contrast, the relative efficacy of the GPCR receptor was determined as the time passed before achieving a certain percentage of maximal Gaq responses.

If the initial step dictates most of the final outcomes, one might wonder why so many intermediate steps exist between the trigger and the effector. One potential advantage of setting up many intermediate events is that they could serve as buffering steps, either by sequestering the mediating elements or by augmenting replenishment of those components lost to attrition, ensuring the success of downstream transduction. In all, we illustrates that the robustness of the signaling system relies critically on the driving power of the trigger, which is a gate to control whether a response can be elicited. However, the overall resolution resides in the late steps on the effector end. Our analysis in this case is generally applicable, given that principles of GPCR transduction mechanisms are highly conserved across different subclasses of G- 
proteins. Such a conceptual framework will underlie the quantitative basis for the robustness of GPCR signaling. 
(A)

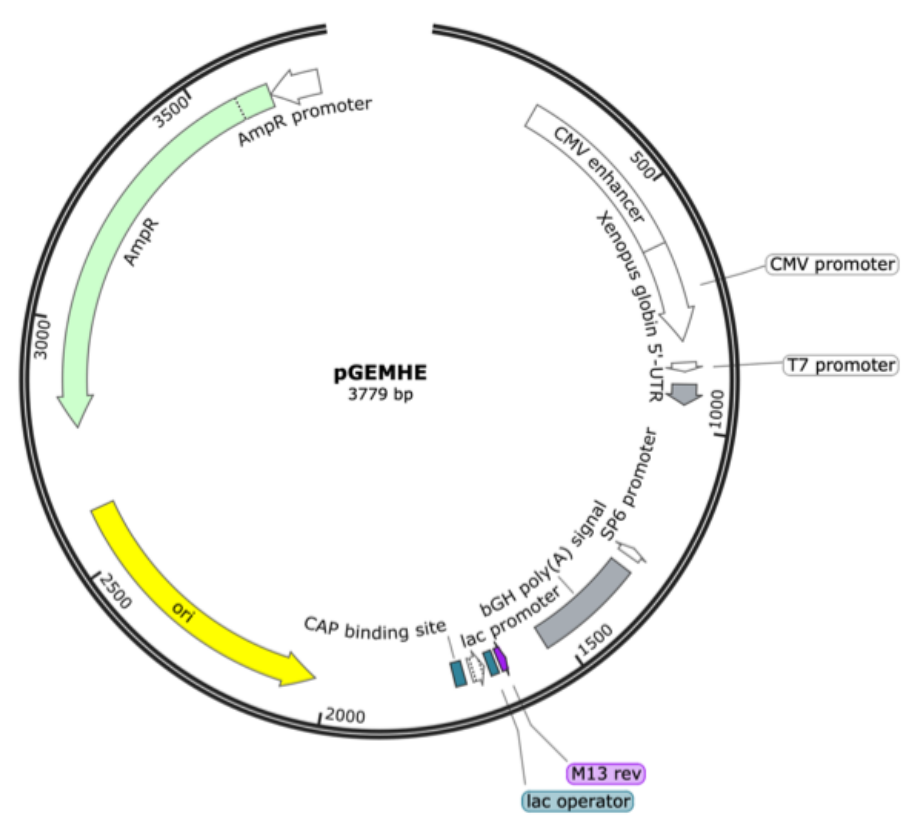

(B)

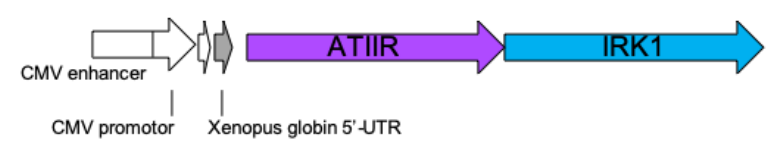

M form of AT1R-IRK1

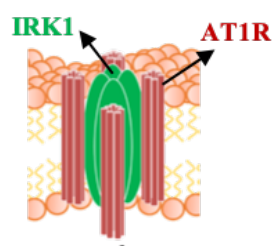

M-form

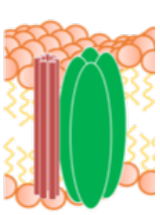

T-form

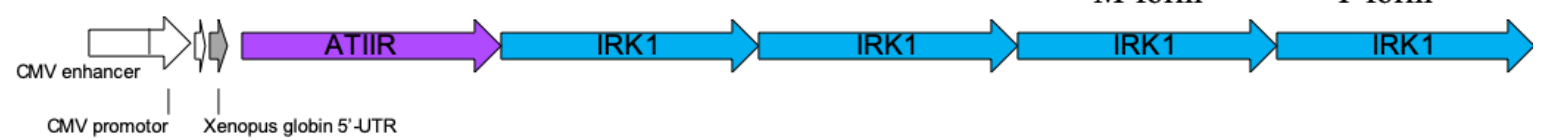

T form of AT1R-IRK1

Figure 1. AT1R-IRK1 construction.

(A) The pXpIV vector contains an origin of replication (ori) (yellow segment) and an ampicillin resistance gene $\left(A m p^{r}\right)$ (Green segment) for maintenance in ampicillinsensitive bacterial strains. Expression in mammalian cells is driven by the CMV immediate early enhancer/promoter, and cRNA transcription uses T7 RNA polymerase. The Xenopus globin 5'-UTR contains the bovine growth hormone polyadenylation signal (bGH poly(A) signal). The Xenopus globin 5'-UTR and the polyA tail including the bovine growth hormone polyadenylation signal were included to improve the stability of RNA in oocytes and to boost the protein expression level [39][40]. The chimeric intron is ATII linked with IRK1, which be inserted between the CMV promoter and the bGH poly(A) signal. (B) Construction of AT1R-IRK1, M-form and T-form. The M-form of AT1R-IRK1 includes one ATIIR gene followed with an IRK1 
gene. The T-form of AT1R-IRK1 is one ATIIR gene followed with four IRK1 gene. Schematic diagram of proposed M-form and T-form of AT1R linked with and IRK1 structure. 
(A)

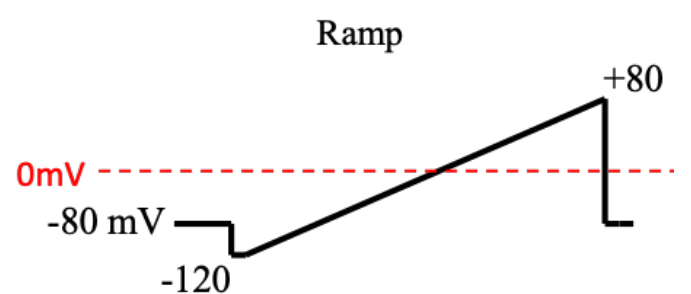

(B)

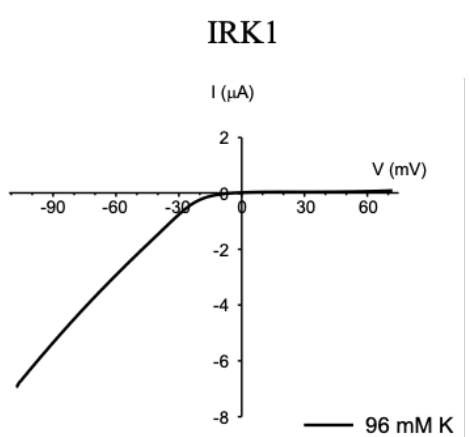

M form of AT1R-IRK1

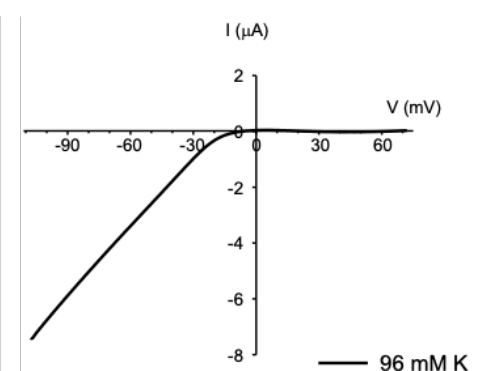

T form of AT1R-IRK1

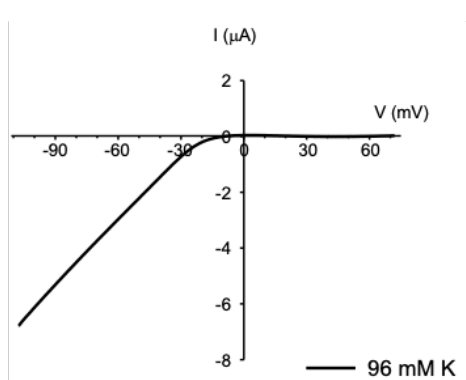

(C)

Uninjected oocyte

Basal current: 0nA

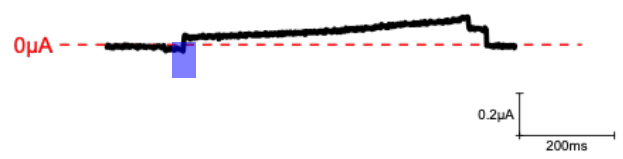

(D)

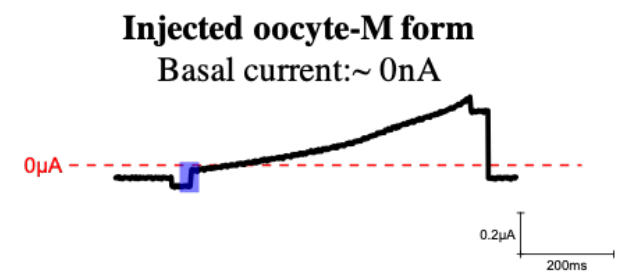

(E)

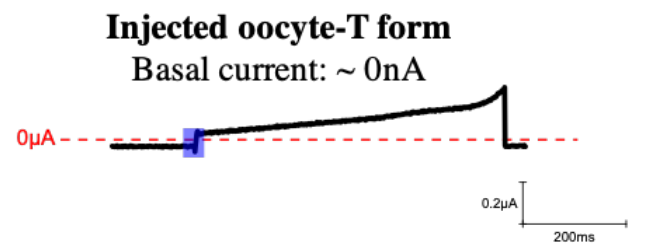

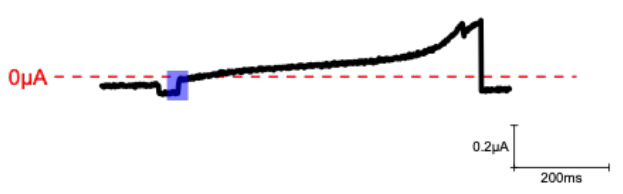

Injected oocyte-M form

IRK1 current: $\sim 6 \mu \mathrm{A}$

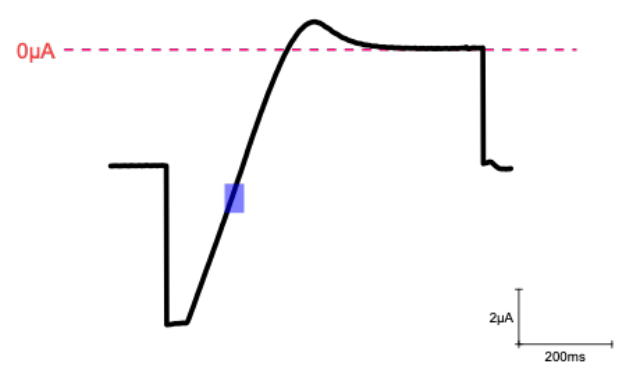

Injected oocyte-T form

IRK1 current: $\sim 5 \mu \mathrm{A}$

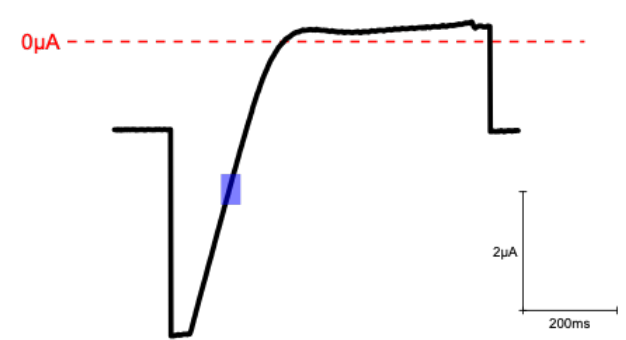


(F)

\section{M form of AT1R-IRK1}

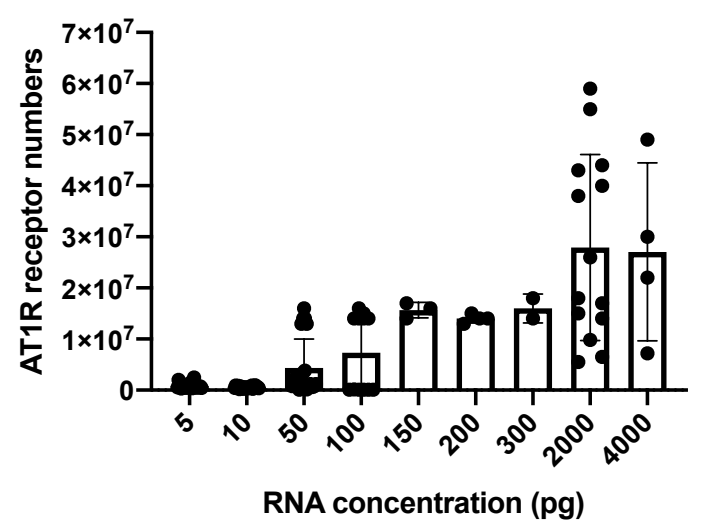

(G)

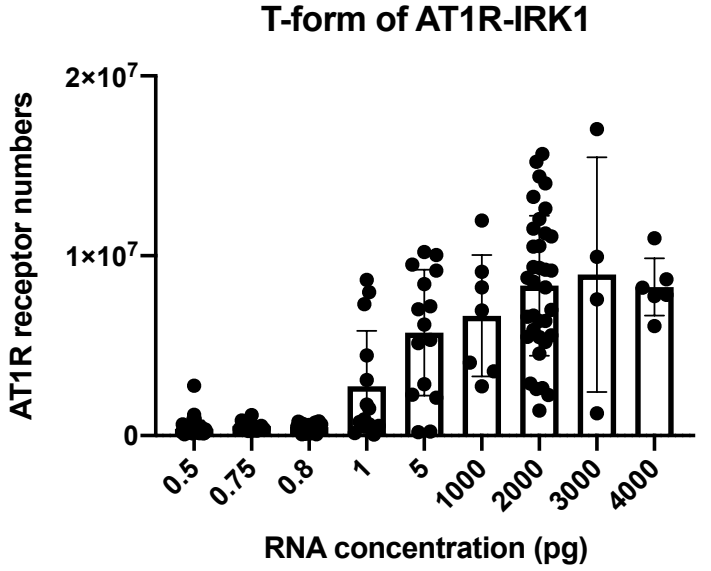

Figure 2. Quantitative analysis of AT1R numbers by recording IRK1 current utilizing two-electrode voltage clamp. (A) We designed a Ramp stimulus program with the voltage change from holding potential $-80 \mathrm{mV}$ switched to $-120 \mathrm{mV}$ at $160 \mathrm{~ms}$, increasing from $-120 \mathrm{mV}$ to $+80 \mathrm{mV}$ in $600 \mathrm{~ms}$, and from $+80 \mathrm{mV}$ switched to the holding potential at $-80 \mathrm{mV}$ at $860 \mathrm{~ms}$. We measured the IRK1 current with the average voltage change from $-114 \mathrm{mV}$ to $-94 \mathrm{mV}$, and we recorded the chloride current with the voltage holding at $+80 \mathrm{mV}$. (B) The I-V curves showed that IRK1 current alteration with voltage change. We compared the IRK1 current in three group, IRK1 alone, M-form of AT1RIRK1 and T-form of AT1R-IRK1. We injected 500 picogram RNA of M-form and Tform in Xenopus oocytes. All of them are perfused with 96mM potassium solution. (C) Uninjected RNA oocytes were used to be a comparing group as injected oocytes. We firstly measured the basal current, nearly close to $0 \mathrm{nA}$ at normal $\mathrm{Na}^{+}(96 \mathrm{mM})$ extracellular solution without pottasium ion in uninjected oocytes, then we switched to normal $\mathrm{K}^{+}(96 \mathrm{mM})$ extracellular solution to record their endogenous potassium current, around 50 to $60 \mathrm{nA}$ with the average voltage change from $-114 \mathrm{mV}$ to $-94 \mathrm{mV}$ (shown in purple box). (D) The oocytes expressed the M-form of AT1R-IRK1were measured the basal current $0 \mathrm{nA}$ at normal $\mathrm{Na}^{+}(96 \mathrm{mM})$ extracellular solution and IRK1 current $6 \mu \mathrm{A}$ in $\mathrm{K}^{+}(96 \mathrm{mM})$ extracellular solution with the average voltage change from $-114 \mathrm{mV}$ to $-94 \mathrm{mV}$ (shown in purple box). (E) The oocytes expressed the T-form of AT1RIRK1were measured the basal current, nearly close to $0 \mathrm{nA}$ in $\mathrm{Na}^{+}(96 \mathrm{mM})$ extracellular solution and IRK1 current $5 \mu \mathrm{A}$ in $\mathrm{K}^{+}(96 \mathrm{mM})$ extracellular solution with the average voltage change from $-114 \mathrm{mV}$ to $-94 \mathrm{mV}$ (shown in purple box). (F, G) We injected 
different concentration of M-form and T-form of AT1R-IRK1 RNA into oocytes. The graph shows the relationship between RNA concentration and AT1R receptor numbers. 
(A)

M-form of AT1R-IRK1

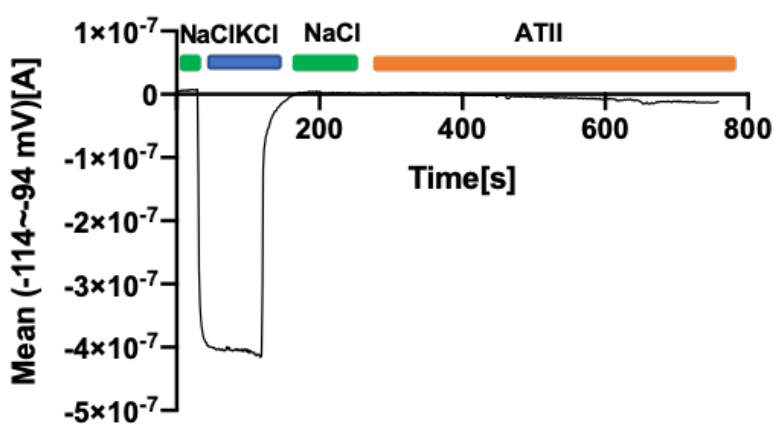

(B)

$\Delta \mathrm{t}=$ Latency

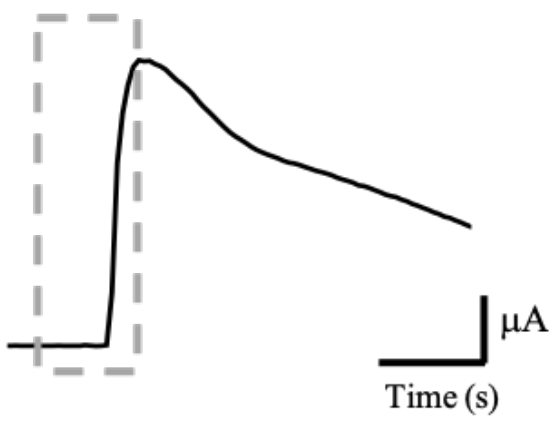

ATII
T-form of AT1R-IRK1

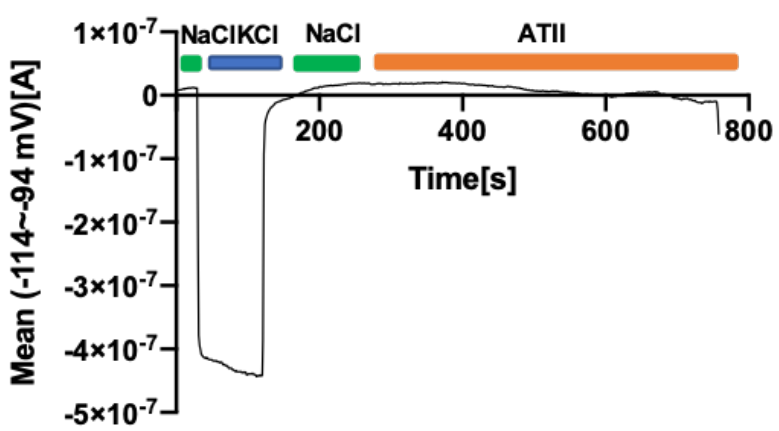

(C)

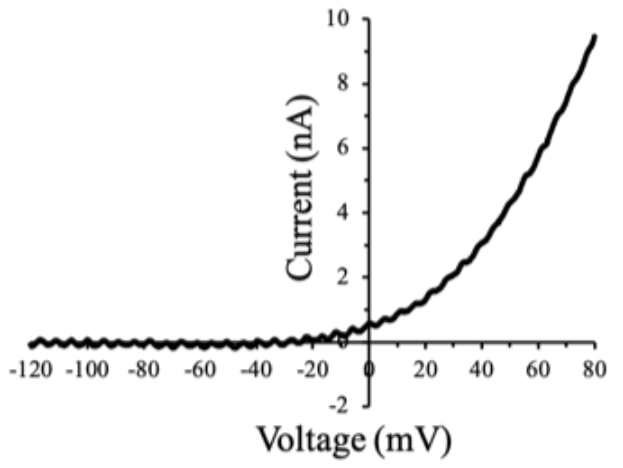

Injected oocyte-T form chloride current

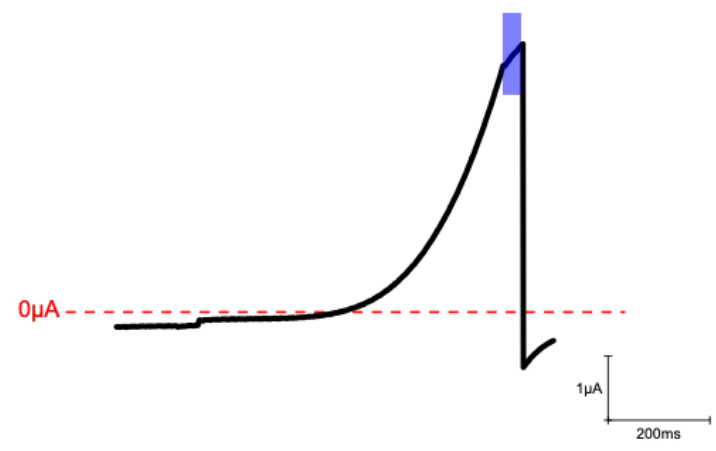

Figure 3. ATII-induced calcium-activated chloride current in M-form and T-form of AT1R-IRK1 receptor. (A) The Ramp Program was set with 610 ramp within around 14 minutes. Xenopus oocytes injected with RNA of M-form or T-form initially perfused with $96 \mathrm{mM} \mathrm{NaCl}$ solution without potassium ion from Ramp 1 to 28 , swithced $96 \mathrm{mM}$ $\mathrm{KCl}$ soultion from Ramp 29 to 106, switched to $96 \mathrm{mM} \mathrm{NaCl}$ solution from Ramp 107 
to 235 , and finally perfused with $1 \mu \mathrm{M}$ AT1R recptor agonist $1 \mu \mathrm{M}$ angiotensin II (ATII) from Ramp 237 to the end. (B) The latency was difined as depicted, the time from administering $1 \mu \mathrm{M}$ ATII to induce the first chloride current response. (C) The IV curve indicated the chloride current in the Ramp program at $+80 \mathrm{mV}$. (D) The oocytes expressing 500pg RNA of M-form and T-form of AT1R-IRK1were measured the chloride current administered $1 \mu \mathrm{M}$ ATII in $96 \mathrm{mM} \mathrm{NaCl}$ solution. The curves are ATIIinduced chloride current of M-form and T-form. The purple area indicates the average voltage $(+59 \mathrm{mV}$ to $+79 \mathrm{mV})$ of measuring chloride current. 
(A)

\section{M-form of AT1R-IRK1}

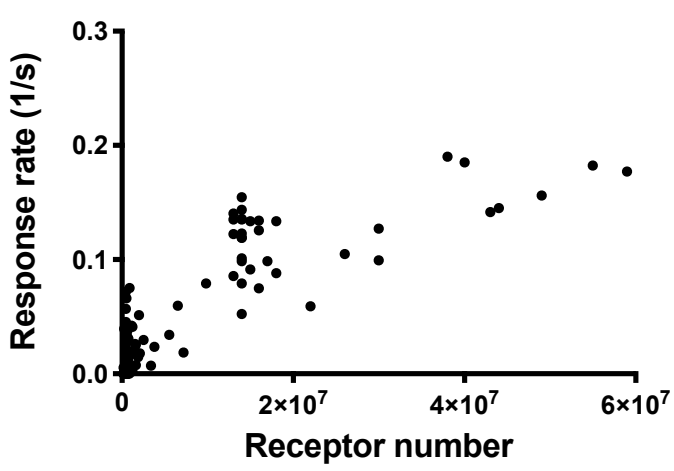

(B)

\section{T-form of AT1R-IRK1}

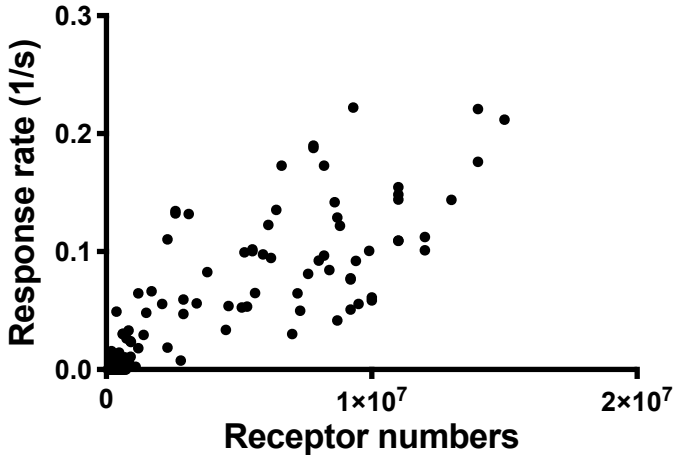

(C)

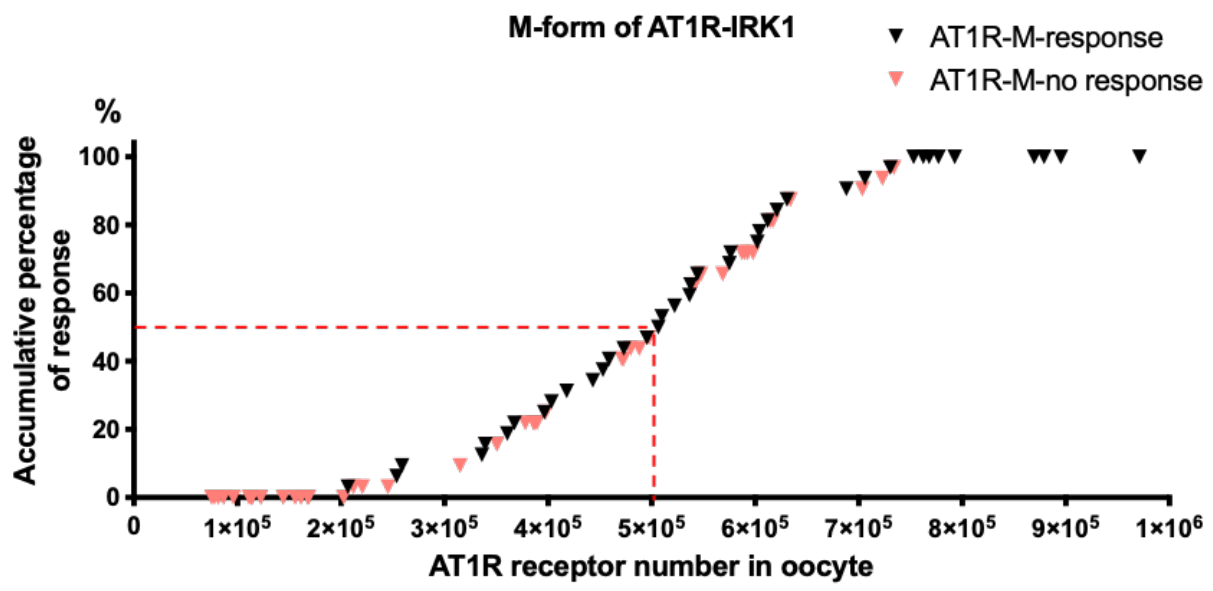

(D)

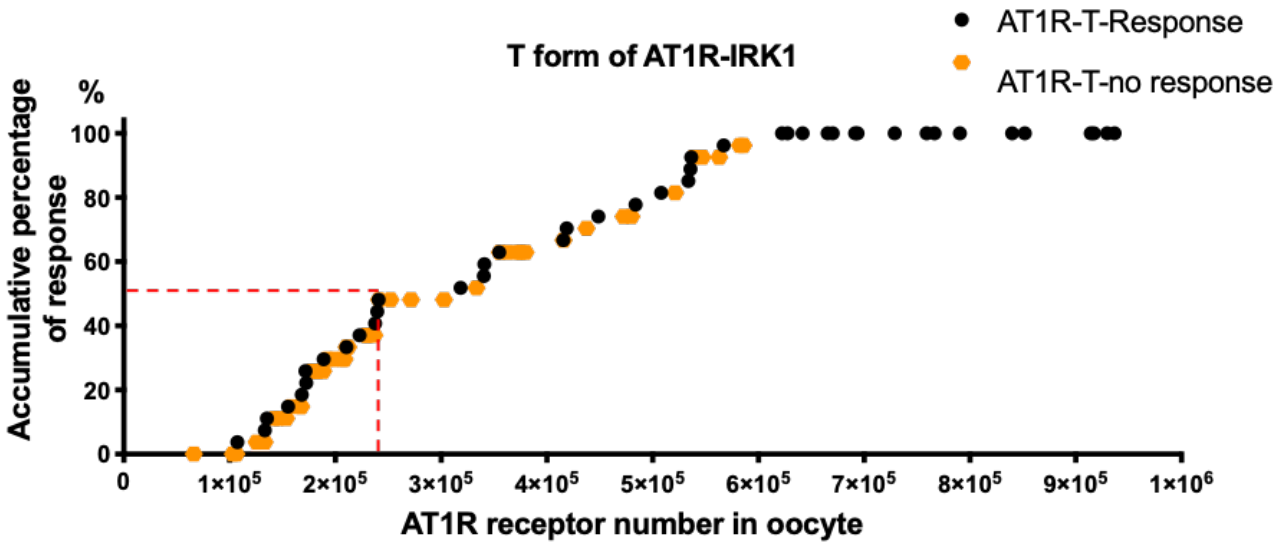


(E)

- T form of AT1R-IRK1

v $M$ form of AT1R-IRK1

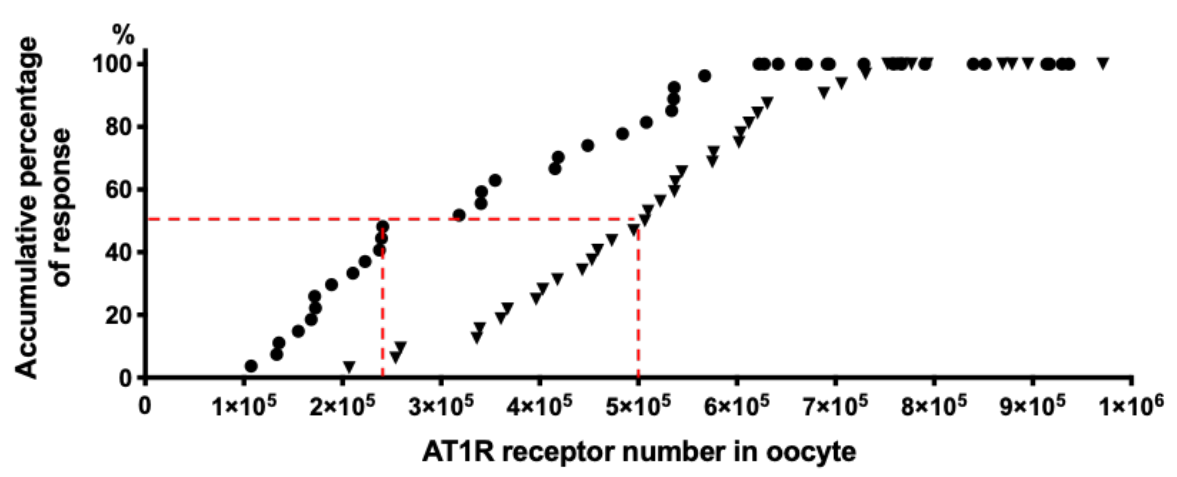

Figure 4. Fewer activated T-form AT1R-IRK1 receptors than M-form are required to induce the first calcium-activated chloride channel $(\mathrm{CaCC})$ response. (A) The relationships between the oocyte response rate upon administration of $1 \mu \mathrm{M}$ angiotensin II and AT1R receptor numbers in our two recombinant AT1R-IRK1 fusion proteins, M-form and T-form. (T-form of AT1R-IRK1, $\mathrm{n}=141$; M-form of AT1RIRK1, $\mathrm{n}=103)(\mathrm{B})(\mathrm{C})$ The thresholds of upstream triggers depend on the intrinsic threshold for $\mathrm{Ca}^{2+}$ activation of a $\mathrm{CaCC}$ response. The probability of production chloride current in M-form and T-form of AT1R-IRK1 Each point represents an oocyte. Black group represents that ATII binds AT1R receptors and produces the chloride current, while orange group represents that ATII binds AT1R receptors but without producing the chloride current. (D) The relationship between the number of AT1RIRK1 fusion proteins and the cumulative percentage of induced $\mathrm{CaCC}$ current recorded for intervals of one hundred thousand receptors. More than seven hundred thousand AT1R fusion proteins are required to induce a maximal cellular response. The threshold number of M-form AT1R-IRK1 is about five hundred thousand, while the threshold number of T-form AT1R-IRK1 is about two hundred fifty thousand. 


\section{Materials and Methods}

AT1R-IRK1 fusion protein construction and heterologous expression of fusion protein

The constructs used in this study included angiotensin II type I receptor (AT1R) (human) and Kir2.1 (GIRK, rat). Complementary DNAs were subcloned into plasmid vector pGEMHE designed for expression in Xenopus oocytes. Plasmids were then linearized with Smil and capped RNA was transcribed with T7 transcription kit (mMessage mMachine; Ambion, Austin, TX). The yield and quality of transcripts was assessed by agarose gel electrophoresis. Stages VI oocytes from Xenopus tropicalis anesthetized by 0.4\% ethyl 3-aminobenzoate methanesulfonate (MS-222)( Sigma-Aldrich; St. Louis, Missouri, USA) were prepared by treatment with $0.1 \mathrm{mg} / \mathrm{ml}$ collagenase (Worthington, type CLS3) for 30 minutes at room temperature with agitation in $82.5 \mathrm{mM} \mathrm{NaCl}, 2 \mathrm{mM}$ $\mathrm{KCl}, 1 \mathrm{mM} \mathrm{MgCl} 2,5 \mathrm{mM}$ Hepes (pH 7.4). Separated and defolliculated oocytes were then rinsed and stored in $82.5 \mathrm{mM} \mathrm{NaCl}, 2 \mathrm{mM} \mathrm{KCl}, 1 \mathrm{mM} \mathrm{MgCl}$, and $5 \mathrm{mM}$ Hepes (pH 7.4) at $18^{\circ} \mathrm{C}$ with $100 \mu \mathrm{g} / \mathrm{ml}$ streptomycin and $100 \mathrm{U} / \mathrm{ml}$ penicillin. Up to $24 \mathrm{hr}$ after collagenase treatment oocytes were injected (Nanoject; Drummond, Broomall, PA) with cRNA in $18.4 \mathrm{nl}$ volumes of different concentrations. For some experiments, it was necessary to inject more RNA to produce functional effects; we have specified the quantities of RNA used in these instances.

\section{Electrophysiology}

All experiments were conducts at room temperature $\left(22^{\circ} \mathrm{C}\right)$. For two-electrode voltage clamp experiments, the potassium-free extracellular solution contained 96 $\mathrm{mM} \mathrm{NaCl}, 1 \mathrm{mM} \mathrm{MgCl} 2,1 \mathrm{mM} \mathrm{CaCl} 2,5 \mathrm{mM}$ HEPES (PH7.4), from which $96 \mathrm{mM} \mathrm{Na}{ }^{+}$ was replaced with $\mathrm{K}^{+}$to make the standard extracellular $\mathrm{K}^{+}(96 \mathrm{~K})$ solution. Recording typically started in $\mathrm{K}^{+}$-free solution and was switched to $96 \mathrm{~K}$ solution to obtain basal potassium currents. Angiotensin II (ATII) was applied in the $96 \mathrm{mM} \mathrm{Na}^{+}$solution. The oocyte membrane potential was held at $-80 \mathrm{mV}$ and given a voltage ramp from -120 $\mathrm{mV}$ to $+80 \mathrm{mV}$ of $600-\mathrm{ms}$ duration applied at $1 \mathrm{~Hz}$. The IRK1 exhibits a significant potassium current flow when the membrane potential is clamped at $-120 \mathrm{mV}$. Utilizing recording $\mathrm{K}^{+}$current subtracted basal current and then divided by a functional IRK1 conductance obtained the numbers of ITK1 channel. Then we used the IRK1 channels numbers to calculate AT1R receptor numbers. 
When ATII were administered to fusion channel-protein, activated G proteins trigger a series of downstream pathways that cause fluctuations in cytosolic calcium concentration were ultimately inducing $\mathrm{CaCC}$ current responses. We used the maximum concentration $1 \mu \mathrm{M}$ angiotensin II as an agonist and measured the average chloride peak current (from +59 to $+79 \mathrm{mV}$ ) of the recorded trace in the RAMP electrical stimulation mode. We can monitor the experimental time variation of this average current. Owing to a series of downstream signal pathways are considered to be the same single response, the time between the administration of the agonist and the induction of the first $\mathrm{Cl}^{-}$current is referred to as the latency. The $\mathrm{Cl}^{-}$current response induction rate is the reciprocal of the latency. Data are acquired and analyzed with the PatchMaster software (HEKA). Data are analyzed and presented by origin (Northampton, Massachusetts, USA).

\section{Author contributions}

HHC and MYC designed the experiments, MYC and YYH performed the molecular and electrophysiological experiments. YYH integrated the experimental results. YYH and $\mathrm{HHC}$ wrote the manuscript. HHC supervised their progression.

\section{Acknowledgements}

We thank Dr. Cheng-Ting Chien for helping this manuscript completed. We also thank Dr. Hsueh-Chi Yen, Dr. Yi-Fang Tsay and Dr. Jun-Yi Leu for stimulating discussion and insightful comments on the manuscript.

Funding: This work was supported by the Career Development Award, Academia Sinica (grant number AS-CDA-103-L03).

Conflict of interest: The authors declare that no conflicts of financial interest exist. 


\section{References}

[1] Lefkowitz RJ. A brief history of G-protein coupled receptors (Nobel Lecture). Angew Chem Int Ed Engl. 2013;52:6366-78.

[2] Pierce KL, Premont RT, Lefkowitz RJ. Seven-transmembrane receptors. Nat Rev Mol Cell Biol. 2002;3:639-50.

[3] Lu ZL, Saldanha JW, Hulme EC. Seven-transmembrane receptors: crystals clarify. Trends Pharmacol Sci. 2002;23:140-6.

[4] Hilger D, Masureel M, Kobilka BK. Structure and dynamics of GPCR signaling complexes. Nat Struct Mol Biol. 2018;25:4-12.

[5] Hopkins AL, Groom CR. The druggable genome. Nat Rev Drug Discov. 2002;1:727-30.

[6] Sridharan R, Zuber J, Connelly SM, Mathew E, Dumont ME. Fluorescent approaches for understanding interactions of ligands with $\mathrm{G}$ protein coupled receptors. Biochim Biophys Acta. 2014;1838:15-33.

[7] Lohse MJ, Nuber S, Hoffmann C. Fluorescence/bioluminescence resonance energy transfer techniques to study G-protein-coupled receptor activation and signaling. Pharmacol Rev. 2012;64:299-336.

[8] Hanson MA, Roth CB, Jo E, Griffith MT, Scott FL, Reinhart G, et al. Crystal structure of a lipid G protein-coupled receptor. Science. 2012;335:851-5.

[9] Cherezov V, Rosenbaum DM, Hanson MA, Rasmussen SG, Thian FS, Kobilka TS, et al. High-resolution crystal structure of an engineered human beta2-adrenergic $\mathrm{G}$ protein-coupled receptor. Science. 2007;318:1258-65.

[10] De A, Loening AM, Gambhir SS. An improved bioluminescence resonance energy transfer strategy for imaging intracellular events in single cells and living subjects. Cancer Res. 2007;67:7175-83.

[11] Okada T, Le Trong I, Fox BA, Behnke CA, Stenkamp RE, Palczewski K. X-Ray diffraction analysis of three-dimensional crystals of bovine rhodopsin obtained from mixed micelles. J Struct Biol. 2000;130:73-80.

[12] Furuta H, Guo DF, Inagami T. Molecular cloning and sequencing of the gene encoding human angiotensin II type 1 receptor. Biochem Biophys Res Commun. 1992;183:8-13.

[13] Guo DF, Furuta H, Mizukoshi M, Inagami T. The genomic organization of human angiotensin II type 1 receptor. Biochem Biophys Res Commun. 1994;200:313-9. 
[14] Bonnardeaux A, Davies E, Jeunemaitre X, Fery I, Charru A, Clauser E, et al. Angiotensin II type 1 receptor gene polymorphisms in human essential hypertension. Hypertension. 1994;24:63-9.

[15] Fredriksson R, Schioth HB. The repertoire of G-protein-coupled receptors in fully sequenced genomes. Mol Pharmacol. 2005;67:1414-25.

[16] Rockman HA, Koch WJ, Lefkowitz RJ. Seven-transmembrane-spanning receptors and heart function. Nature. 2002;415:206-12.

[17] Holtz J, Goetz RM. The endothelium and the renin-angiotensin system. Arzneimittelforschung. 1994;44:397-402.

[18] O'Brien SL, Johnstone EKM, Devost D, Conroy J, Reichelt ME, Purdue BW, et al. BRET-based assay to monitor EGFR transactivation by the AT1R reveals Gq/11 protein-independent activation and AT1R-EGFR complexes. Biochem Pharmacol. 2018;158:232-42.

[19] Szekeres M, Nadasy GL, Turu G, Soltesz-Katona E, Benyo Z, Offermanns S, et al. Endocannabinoid-mediated modulation of $\mathrm{Gq} / 11$ protein-coupled receptor signalinginduced vasoconstriction and hypertension. Mol Cell Endocrinol. 2015;403:46-56.

[20] Hunyady L, Catt KJ. Pleiotropic AT1 receptor signaling pathways mediating physiological and pathogenic actions of angiotensin II. Mol Endocrinol. 2006;20:95370.

[21] Crowley SD, Tharaux PL, Audoly LP, Coffman TM. Exploring type I angiotensin (AT1) receptor functions through gene targeting. Acta Physiol Scand. 2004;181:56170.

[22] Mackrill JJ, Challiss RA, O'Connell D A, Lai FA, Nahorski SR. Differential expression and regulation of ryanodine receptor and myo-inositol 1,4,5-trisphosphate receptor $\mathrm{Ca} 2+$ release channels in mammalian tissues and cell lines. Biochem $\mathrm{J}$. 1997;327 ( Pt 1):251-8.

[23] Eberhard DA, Holz RW. Intracellular Ca2+ activates phospholipase C. Trends Neurosci. 1988;11:517-20.

[24] Kang M, Othmer HG. The variety of cytosolic calcium responses and possible roles of PLC and PKC. Phys Biol. 2007;4:325-43.

[25] Mikoshiba K. Role of IP3 receptor signaling in cell functions and diseases. Adv Biol Regul. 2015;57:217-27. 
[26] Ewald DA, Pang IH, Sternweis PC, Miller RJ. Differential G protein-mediated coupling of neurotransmitter receptors to $\mathrm{Ca} 2+$ channels in rat dorsal root ganglion neurons in vitro. Neuron. 1989;2:1185-93.

[27] El Far O, Betz H. G-protein-coupled receptors for neurotransmitter amino acids:

C-terminal tails, crowded signalosomes. Biochem J. 2002;365:329-36.

[28] Birnbaumer L, Abramowitz J, Brown AM. Receptor-effector coupling by G proteins. Biochim Biophys Acta. 1990;1031:163-224.

[29] Spiegel AM, Shenker A, Weinstein LS. Receptor-effector coupling by G proteins: implications for normal and abnormal signal transduction. Endocr Rev. 1992;13:53665.

[30] Spiegel AM. Receptor-effector coupling by G-proteins: implications for neuronal plasticity. Prog Brain Res. 1990;86:269-76.

[31] Spiegel AM. Receptor-effector coupling by G-proteins implications for endocrinology. Trends Endocrinol Metab. 1989;1:72-6.

[32] Birnbaumer L, Codina J, Mattera R, Yatani A, Graf R, Olate J, et al. Receptoreffector coupling by G proteins: purification of human erythrocyte Gi-2 and Gi-3 and analysis of effector regulation using recombinant alpha subunits synthesized in Escherichia coli. Cold Spring Harb Symp Quant Biol. 1988;53 Pt 1:229-39.

[33] Chuang H, Jan YN, Jan LY. Regulation of IRK3 inward rectifier K+ channel by $\mathrm{m} 1$ acetylcholine receptor and intracellular magnesium. Cell. 1997;89:1121-32.

[34] He C, Zhang H, Mirshahi T, Logothetis DE. Identification of a potassium channel site that interacts with $\mathrm{G}$ protein betagamma subunits to mediate agonist-induced signaling. J Biol Chem. 1999;274:12517-24.

[35] Shin HG, Lu Z. Mechanism of the voltage sensitivity of IRK1 inward-rectifier K+ channel block by the polyamine spermine. J Gen Physiol. 2005;125:413-26.

[36] Fakler B, Brandle U, Glowatzki E, Weidemann S, Zenner HP, Ruppersberg JP. Strong voltage-dependent inward rectification of inward rectifier $\mathrm{K}+$ channels is caused by intracellular spermine. Cell. 1995;80:149-54.

[37] Miledi R, Parker I, Sumikawa K. Properties of acetylcholine receptors translated by cat muscle mRNA in Xenopus oocytes. EMBO J. 1982;1:1307-12.

[38] Gundersen CB, Miledi R, Parker I. Messenger RNA from human brain induces drug- and voltage-operated channels in Xenopus oocytes. Nature. 1984;308:421-4. 
[39] Krieg PA, Melton DA. Functional messenger RNAs are produced by SP6 in vitro transcription of cloned cDNAs. Nucleic Acids Res. 1984;12:7057-70.

[40] Liman ER, Tytgat J, Hess P. Subunit stoichiometry of a mammalian K+ channel determined by construction of multimeric cDNAs. Neuron. 1992;9:861-71.

[41] MacKinnon R. Nobel Lecture. Potassium channels and the atomic basis of selective ion conduction. Biosci Rep. 2004;24:75-100.

[42] Terrillon S, Bouvier M. Roles of G-protein-coupled receptor dimerization. EMBO Rep. 2004;5:30-4.

[43] Gonzalez-Maeso J. GPCR oligomers in pharmacology and signaling. Mol Brain. 2011;4:20.

[44] Milligan G. G protein-coupled receptor dimerisation: molecular basis and relevance to function. Biochim Biophys Acta. 2007;1768:825-35.

[45] Overton MC, Chinault SL, Blumer KJ. Oligomerization of G-protein-coupled receptors: lessons from the yeast Saccharomyces cerevisiae. Eukaryot Cell. 2005;4:1963-70.

[46] Szidonya L, Cserzo M, Hunyady L. Dimerization and oligomerization of Gprotein-coupled receptors: debated structures with established and emerging functions. J Endocrinol. 2008;196:435-53.

[47] Gurevich VV, Gurevich EV. GPCR monomers and oligomers: it takes all kinds. Trends Neurosci. 2008;31:74-81.

[48] Moreira IS. Structural features of the G-protein/GPCR interactions. Biochim Biophys Acta. 2014;1840:16-33.

[49] Ghanouni P, Steenhuis JJ, Farrens DL, Kobilka BK. Agonist-induced conformational changes in the G-protein-coupling domain of the beta 2 adrenergic receptor. Proc Natl Acad Sci U S A. 2001;98:5997-6002.

[50] Hoffmann C, Zurn A, Bunemann M, Lohse MJ. Conformational changes in Gprotein-coupled receptors-the quest for functionally selective conformations is open. Br J Pharmacol. 2008;153 Suppl 1:S358-66.

[51] Wess J, Han SJ, Kim SK, Jacobson KA, Li JH. Conformational changes involved in G-protein-coupled-receptor activation. Trends Pharmacol Sci. 2008;29:616-25.

[52] Lambert DG. Signal transduction: G proteins and second messengers. Br J Anaesth. 1993; 71:86-95. 
[53] Shibata T, Suzuki C, Ohnishi J, Murakami K, Miyazaki H. Identification of regions in the human angiotensin II receptor type 1 responsible for Gi and Gq coupling by mutagenesis study. Biochem Biophys Res Commun. 1996;218:383-9.

[54] McLaughlin JN, Thulin CD, Bray SM, Martin MM, Elton TS, Willardson BM. Regulation of angiotensin II-induced G protein signaling by phosducin-like protein. $\mathrm{J}$ Biol Chem. 2002;277:34885-95.

[55] Guo DF, Sun YL, Hamet P, Inagami T. The angiotensin II type 1 receptor and receptor-associated proteins. Cell Res. 2001;11:165-80. 